\title{
Allergic contact dermatitis caused by dorzolamide eyedrops
}

This article was published in the following Dove Press journal:

Clinical Ophthalmology

2 April 2015

Number of times this article has been viewed

\section{Seung-Jun Lee \\ Moosang Kim}

Department of Ophthalmology, School of Medicine, Kangwon National University, Chuncheon, Korea
Correspondence: Moosang Kim Baengnyeong-ro I56, Chuncheon-Si, Gangwon-Do Kangwon National University Hospital, Chuncheon 200-722, Korea

Tel +82 332582014

Fax +82 332582000

Email kimmoo-79@hanmail.net
Abstract: The side effects of topical dorzolamide hydrochloride, such as conjunctivitis, eyelid edema, and eye lid irritation, are well known. However, allergic contact dermatitis due to dorzolamide is rare, although the product has been commonly used worldwide in patients with glaucoma. To the best of our knowledge, this is the first report of allergic contact dermatitis caused by topical dorzolamide hydrochloride in Korea. Herein we report a case of allergic contact dermatitis due to topical dorzolamide eyedrops.

Keywords: allergic contact dermatitis, dorzolamide, side effects

\section{Introduction}

Dorzolamide is a sulfonamide and topical carbonic anhydrase II inhibitor. It is indicated for the reduction of elevated intraocular pressure in patients with open-angle glaucoma or ocular hypertension who are insufficiently responsive to beta-blockers. ${ }^{1}$ The side effects of topical dorzolamide hydrochloride, such as conjunctivitis, eyelid edema, and eye lid irritation, are well known. ${ }^{2}$ However, allergic contact dermatitis due to dorzolamide is rare, although it has been commonly used worldwide in patients with glaucoma. Herein we report a case of allergic contact dermatitis due to topical dorzolamide eyedrops.

\section{Case report}

A 77-year-old woman presented with ocular discomfort and periorbital eczematous swelling in both eyes (Figure 1A). She had no history of atopy or previously known allergy contact dermatitis. At presentation, visual acuity was 20/100 in both eyes. The intraocular pressure was $17 \mathrm{mmHg}$ in the right eye and $20 \mathrm{mmHg}$ in the left eye. One month earlier, bilateral phacovitrectomy and intravitreal gas tamponade had been performed at our hospital to remove the tractional epiretinal membrane. Postoperatively, dorzolamide eyedrops was applied twice a day to manage her intraocular pressure for about a month, by which time an eczema-like periorbital swelling of the both eyes had occurred. She had an erythematous rash on both eyelids, and suffered from severe pruritus and burning sensation. We initially assumed that the patient's symptoms to indicate an early stage of preseptal cellulitis, so treated her with systemic and topical antibiotics. The patient's symptoms nonetheless showed no improvement. When dorzolamide was discontinued, however, the eczematous swelling and itching sensation disappeared within a week (Figure 1B). We switched dorzolamide to tafluprost eyedrops (Taflotan ${ }^{\circledR}$, Santen Pharmaceutical Co Ltd, Osaka, Japan) and performed a patch test. Patch testing was carried out according to the International Contact Dermatitis Research Group recommendations. Using the Finn chamber method, the patient was tested for a standard series of allergens, to benzalkonium chloride $0.1 \%$ in water and to pure dorzolamide 

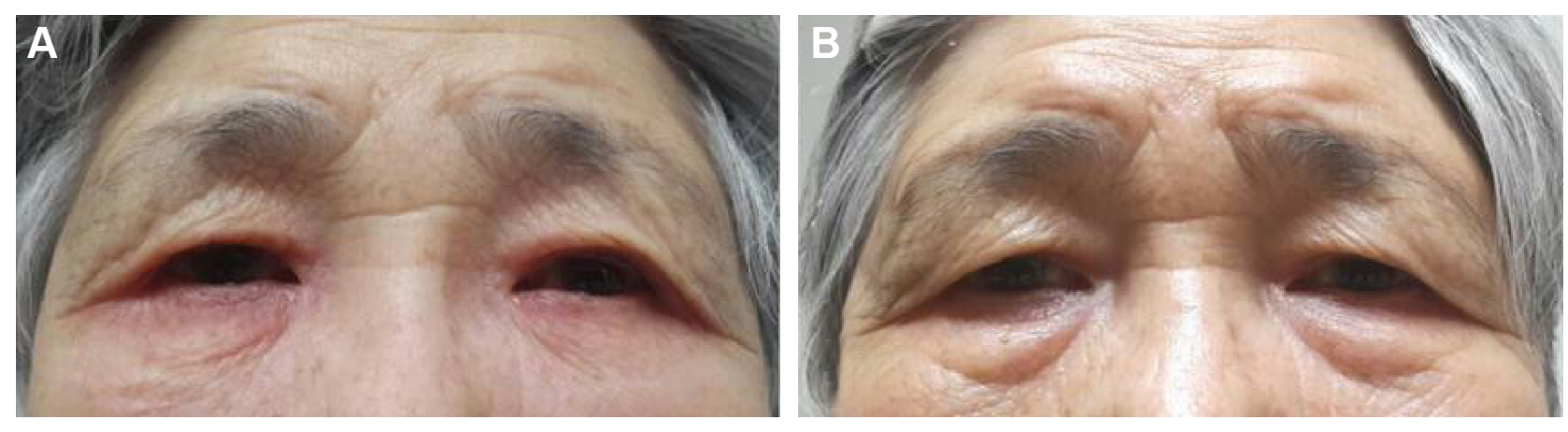

Figure I (A) Bilateral eczematous periorbital swelling after instillation of dorzolamide eyedrops. (B) Improved periorbital swelling after cessation of dorzolamide eyedrops.

hydrochloride $1 \%$. The duration of occlusion was 1 day and results were read at days 2 and 5 . The patch test with pure dorzolamide was positive, with erythema, edema, and papules at days 2 and 5, while the patch test with benzalkonium chloride $0.1 \%$ was negative. Therefore, we diagnosed the patient as having dorzolamide-induced contact dermatitis.

\section{Discussion}

According to the World Health Organization and the Glaucoma Foundation, glaucoma affects $67-105$ million people worldwide. ${ }^{3}$ Maintenance therapy with a topical antiglaucoma drug is crucial to prevent permanent vision loss. Currently, prostaglandin F2 $\alpha$ analogs are the most commonly used drugs for glaucoma. However, we used dorzolamide eyedrops instead of latanoprost to manage our patient's intraocular pressure in the early postoperative period. Endogenous prostaglandin release induced by postoperative anterior segment inflammation can lead to blood aqueous breakdown, inflammatory mediators reaching the macula, and cystoid macular edema. It is known that long-term use of topical latanoprost causes cystoid macular edema after intraocular surgery. ${ }^{4}$

Based on patch test results, we confirmed the diagnosis of allergic contact dermatitis due to topical dorzolamide drops, and changed the patient's antiglaucoma medication. Delaney et al reported 14 cases of periorbital dermatitis caused by topical dorzolamide hydrochloride. ${ }^{5}$ To the best of our knowledge, this is the first report of allergic contact dermatitis caused by topical dorzolamide hydrochloride in Korea. The common adverse effects of topical dorzolamide hydrochloride are tearing, photophobia, conjunctivitis, stinging, blurred vision, punctate epithelial keratitis, and corneal decompensation. ${ }^{2}$ Rarely, allergic contact dermatitis due to dorzolamide may cause pruritic skin eruptions.

Because of its relative infrequency, dorzolamide-induced contact dermatitis may be misdiagnosed as preseptal cellulitis or chalazion. If the patient have an sensitivity to sulfur drugs, we have to use topical dorzolamide eyedrops with caution after intraocular surgery. Even though there are not many reports, ${ }^{6-11}$ we have to be aware of the possibility of allergic contact dermatitis due to topical dorzolamide eyedrops. In addition, patients on dorzolamide should be warned of this potential late side effect.

\section{Conclusion}

In patients who do not respond to treatment for continuous periorbital swelling, it is necessary to differentiate dorzolamide-induced allergic contact dermatitis with careful examination and history-taking.

\section{Disclosure}

The authors report no conflicts of interest in this work.

\section{References}

1. Pfeiffer N. Dorzolamide: development and clinical application of a topical carbonic anhydrase inhibitor. Surv Ophthalmol. 1997;42: 137-151.

2. Konowal A, Morrison JC, Brown SV, et al. Irreversible corneal decompensation in patients treated with topical dorzolamide. $\mathrm{Am}$ J Ophthalmol. 1999;127:403-406.

3. Digiuni M, Fogagnolo P, Rossetti L. A review of the use of latanoprost for glaucoma since its launch. Expert Opin Pharmacother. 2012; 13:723-745.

4. Erdogan H, Ozec AV, Caner C, Toker MI, Arici MK, Topalkara A. Effect of latanoprost/timolol and dorzolamide/tiomolol on intraocular pressure after phacoemulsification surgery. Int J Ophthalmol. 2011;4: 190-194.

5. Delaney YM, Salmon JF, Mossa F, et al. Periorbital dermatitis as a side effect of topical dorzolamide. Br J Ophthalmol. 2002;86:378-380.

6. Kluger N, Guillot B, Raison-Peyron N. Systemic contact dermatitis to dorzolamide eye drops. Contact Dermatitis. 2008;58:167-168.

7. Kalavala M, Statham BN. Allergic contact dermatitis from timolol and dorzolamide eye drops. Contact Dermatitis. 2006;54:345.

8. Linares Mata T, Pardo Sánchez J, de la Cuadra Oyanguren J. Contact dermatitis caused by allergy to dorzolamide. Contact Dermatitis. 2005;52: $111-112$.

9. Mancuso G, Berdondini RM. Allergic contact blepharoconjunctivitis from dorzolamide. Contact Dermatitis. 2001;45:243.

10. Shimada M, Higaki Y, Kawashima M. Allergic contact dermatitis due to dorzolamide eyedrops. Contact Dermatitis. 2001;45:52.

11. Aalto-Korte K. Contact allergy to dorzolamide eyedrops. Contact Dermatitis. 1998;39:206. 
Clinical Ophthalmology

\section{Publish your work in this journal}

Clinical Ophthalmology is an international, peer-reviewed journal covering all subspecialties within ophthalmology. Key topics include: Optometry; Visual science; Pharmacology and drug therapy in eye diseases; Basic Sciences; Primary and Secondary eye care; Patien Safety and Quality of Care Improvements. This journal is indexed on

Submit your manuscript here: http://www.dovepress.com/clinical-ophthalmology-journal

PubMed Central and CAS, and is the official journal of The Society of Clinical Ophthalmology (SCO). The manuscript management system is completely online and includes a very quick and fair peer-review system, which is all easy to use. Visit http://www.dovepress.com/ testimonials.php to read real quotes from published authors. 